\title{
Corrosion Protection of Steel by Calcareous Electrodeposition in Seawater (Part 3)
}

\author{
-Effects of Dilution on Deposition- \\ Kenichi Akamine * and Isamu Kashiki** \\ * Material Processing \& Evaluation Group, Production Engineering Department, \\ Production Engineering Center, Ishikawajima-Harima Heavy Industries Co., Ltd. \\ ** Department of Chemical Oceanography, Faculty of Fisheries, Hokkaido University
}

\begin{abstract}
To examine the applicability of the cathodic protection, which is accompanied with calcareous deposition, to ferrous structures in estuary areas, a study has been made concerning the effects of seawater dilution on the amount, the composition and the structure of the deposit. The dilution resulted in few effects on the amount of the deposit, until the dilution decreased the salinity to $1 / 10$ of the original value. On the other hand, the $\mathrm{Mg} / \mathrm{Ca}$ ratio of the deposit was greatly influenced by the dilution. As for the structure, the deposit thickness was sharply increased when the dilution decreased the salinity less than $1 / 10$ of the original value. These results were discussed on the basis of the difference in the crystallization rate and the hydrophilic character between $\mathrm{CaCO}_{3}$ and $\mathrm{Mg}(\mathrm{OH})_{2}$.
\end{abstract}

Key words : steel, cathodic protection, calcareous deposit, estuary, dilution, calcium carbonate, magnesium hydroxide

\section{Introduction}

Recently, there has been a conspicuous trend of constructing gigantic marine structures, in particular, in estuary areas. Estuary seawater is chiefly characterized by the lowered salinity due to fresh water influx from lands adjacent to the areas. It is widely recognized that cathodic protection $(\mathrm{CP})$ is an important method of preventing corrosion of structures exposed in seawater ${ }^{1,2), 3)}$, but there have been few studies, that we are aware of, on its applicability in estuary areas. In the CP method, accompanying calcareous deposition on structures plays an important role $^{2), 3)}$. It is naturally expected that the salinity lowering in estuary areas should give considerable effects on the calcareous deposit formation. The objective of this study is to examine the effect of seawater dilution on the calcareous deposition and on the structure of the deposit, and to examine the applicability of the CP method to ferrous structures in estuary areas.

\section{Experimental}

\subsection{Materials}

The natural seawater used for $\mathrm{CP}$ experiments was taken from the offing of Hachijo Island, Tokyo, and filtrated through a membrane filter with $0.45 \mu \mathrm{m}$ pore size. The salinity and the $\mathrm{pH}$ were about $3.4 \%$ and 8.2 , respectively. To obtain seawaters with various low salinities, the original seawater was diluted with distilled water. Steel specimens used for the cathodes in the experiments were the same as those used in the previous studies ${ }^{4), 5)}$. Fig. 1 shows a schematic drawing for one of the specimens. It was a

\footnotetext{
* 1, Shin-nakahara-cho, Isogoku, Yokohama, 235-8501 Japan

** 3-1-1, Minato-cho, Hakodate, 041-8611 Japan
}

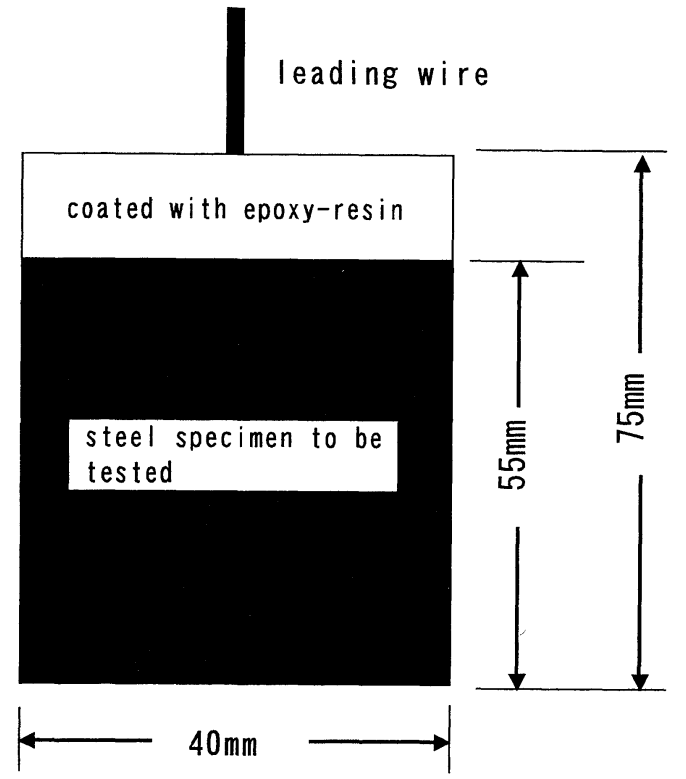

Fig. 1 Schematic drawing for the used steel specimen.

$75 \mathrm{~mm}$-by-40mm-by-2.6mm sand-blasted steel plate at the upper end of which a copper leading wire was soldered, and the upper $20 \mathrm{~mm}$ part of the plate was coated with epoxy-resin paint. The effective cathode area of a specimen to be tested amounts approximately to $48 \mathrm{~cm}^{2}$. Cast magnesium rods (MAGNAP-2) supplied from Nakaboh-Tech Co., Ltd. were used for the anodes with no further treatment. They were $150 \mathrm{~mm}$ in length, and $20 \mathrm{~mm}$ in diameter. Any other chemical reagents used were of analytical grade.

\subsection{Calcareous deposit formation}

Calcareous deposits on the steel specimens were formed in closed systems. $2400 \mathrm{dm}^{3}$ of natural or diluted seawater was measured into a rectangular plastic vessel (the volume capacity: $3 \mathrm{dm}^{3}$ ). A steel specimen and a magnesium anode 
were fixed vertically in it, the distance between the two being $8 \mathrm{~cm}$. The current between the two electrodes was regulated at $0.5 \mathrm{~A} / \mathrm{m}^{2}$ with a galvanostat. All the experiments were carried out in quiescent seawaters with no agitation at $298 \mathrm{~K}$, the electrodeposition time being $96 \mathrm{~h}$.

\subsection{Chemical analysis of calcareous deposits}

After finishing calcareous deposit formation, the steel specimen was washed with distilled water, and immersed in $100 \mathrm{dm}^{3}$ of $2 \mathrm{~mol} / \mathrm{dm}^{3}$ hydrochloric solution for $5 \mathrm{~min}$ to dissolve the calcareous film. The concentration of magnesium and calcium was determined by a titration method using an EDTA solution. Total amount of the film was estimated on the assumption that all the magnesium and calci$\mathrm{um}$ be in the forms of $\mathrm{Mg}(\mathrm{OH})_{2}$ and $\mathrm{CaCO}_{3}$, respectively.

\subsection{Structural analysis of calcareous deposits}

After finishing the electrodeposition, the specimen together with the deposit was air-dried at room temperature, and the variation of the total weight, $W$, with time, $t$, was followed. The point, $t_{\mathrm{a}}$, where the drying rate, $d W / d t$, changed from almost constant to falling rate gives the deposit weight including the pore water, $W_{\mathrm{d}}^{5)}$.

\section{Results and discussion}

\subsection{Effect of dilution on deposit composition}

Fig. 2 shows the dependence of total amount of calcareous deposit, $W_{\mathrm{T}}$ (presented by the open circles), upon the dilution ratio, $d$, of seawater, where the total electricity passed, $Q$, was kept constant as $Q=172800 \mathrm{C} / \mathrm{m}^{2}$ for all experiments. The dilution ratio, $d$, is defined by

$$
\mathrm{d}=C / C_{0}
$$

where $C_{0}$ and $C$ are the salinities of original and diluted seawater, respectively. Also presented by the closed circles in Fig. 2 are for the current efficiency, C.E., of the electrodeposition defined by

$$
\text { C.E. }=W_{\mathrm{T}} \times 100 / W_{\mathrm{T}}
$$

where $W_{\mathrm{T}}$ is the total amount of calcareous deposit calcu-

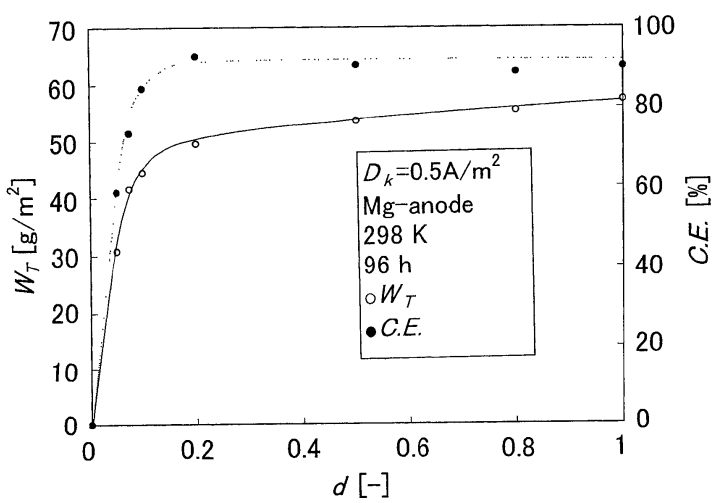

Fig. 2 Effect of seawater dilution on the amount of calcareous deposit formed. $W_{\mathrm{T}}(\bigcirc)$ refers to the total amount of calcareous deposit, and $d$ is the dilution ratio. The current efficiency $(\bullet), C . E$., is also presented. lated on the assumption that the electric quantity of $2 \times$ $96485 \mathrm{C}$ should be required to deposit 1 mole of either $\mathrm{CaCO}_{3}$ or $\mathrm{Mg}(\mathrm{OH})_{2}$. This figure shows that until seawater is diluted down to $d=0.1$, both $W_{\mathrm{T}}$ and C.E. remain almost constant, and thereafter they both decrease sharply to 0 . These results suggest that the method of cathodic protection with calcareous deposition is applicable, in principle, to ferrous structures in estuary areas with the salinity more than about $1 / 10$ of the standard seawater. The details of Fig. 2 are presented in Fig. 3, where $W_{\mathrm{i}}$ is the amount of $\mathrm{CaCO}_{3}$ or $\mathrm{Mg}(\mathrm{OH})_{2}$ deposited on the cathode, and the subscripts of $\mathrm{Ca}$ and $\mathrm{Mg}$, respectively denote $\mathrm{CaCO}_{3}$ and $\mathrm{Mg}(\mathrm{OH})_{2}$. Although the total amount of deposit remains almost unvaried from $d=1$ to 0.1 , considerable variation is found in the amount of $\mathrm{CaCO}_{3}$ or $\mathrm{Mg}(\mathrm{OH})_{2}$ in the same dilution range. With decreasing $d$, the amount of $\mathrm{Mg}(\mathrm{OH})_{2}$ deposited increases, while the amount of $\mathrm{CaCO}_{3}$ decreases. Fig. 4 shows that it is difficult to ascribe this variation in the deposit composition mainly to the variation in $\mathrm{pH}$ of seawater due to the dilution. As the result of the buffer action of the carbonate and bicarbonate ions in seawater, the dilution gives few effects on the $\mathrm{pH}$ of seawater until $d$ decreases down to 0.1 .

In general, a calcareous deposition process can be

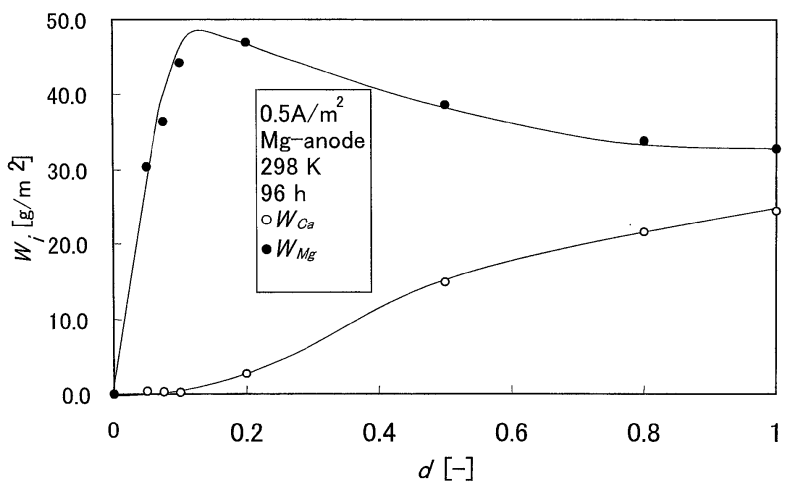

Fig. 3 Representation for each component amount of the calcareous deposit presented in Fig. 2. $W_{\mathrm{i}}$ denotes each component amount, and the open and the closed circles refer to those of $\mathrm{CaCO}_{3}$ and $\mathrm{Mg}(\mathrm{OH})_{2}$, respectively.

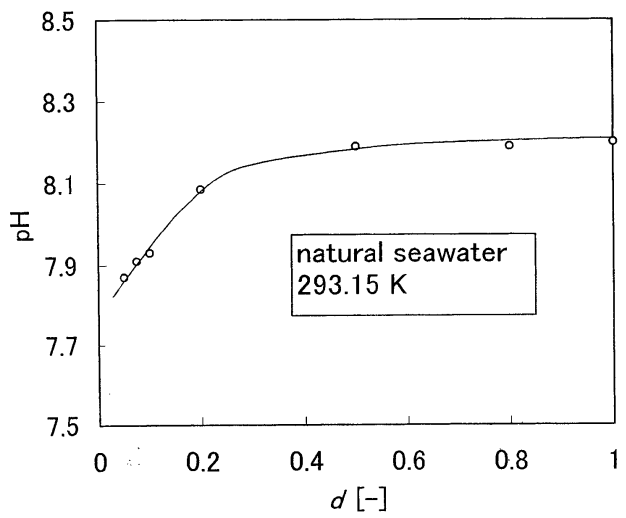

Fig. 4 Variation in seawater $\mathrm{pH}$ with the dilution ratio, $d$. 
regarded as a succession of the following three steps:

1. nucleation and its growth to colloidal size (crystallization),

2. electrophoretic movement of the formed colloidal particles to a cathode, and

3. deposition of the particles onto the cathode surface.

It is widely recognized that the $\mathrm{CaCO}_{3}$ formation rate is sluggish in seawater ${ }^{6), 7), 8)}$, as compared with that of $\mathrm{Mg}(\mathrm{OH})_{2}$. For the rate constant of the former, $k_{\mathrm{Ca}}$, as small as $k_{\mathrm{Ca}}=1.13 \times 10^{-12} \mathrm{~mol} / \mathrm{cm}^{2} \cdot \mathrm{s}$ has been reported, while for that of the latter, $k_{\mathrm{Mg}}=3.7 \times 10^{7} \mathrm{~mol} / \mathrm{cm}^{2} \cdot \mathrm{s}^{8)}$, where $k_{\mathrm{Ca}}$ and $k_{\mathrm{Mg}}$ are the rate constants of the formation reactions of $\mathrm{CaCO}_{3}$ and $\mathrm{Mg}(\mathrm{OH})_{2}$, respectively. Therefore, we can reasonably assume that, for $\mathrm{CaCO}_{3}$ deposition, the first step is the rate-determining one. Hence, the overall deposition rate of $\mathrm{CaCO}_{3}, r_{\mathrm{Ca}}$, can be expressed by ${ }^{8)}$

$$
r_{\mathrm{Ca}}=k_{\mathrm{Ca}}\left[\mathrm{Ca}^{2+}\right]\left[\mathrm{CO}_{3}^{2-}\right]
$$

where the brackets represent the concentrations for the corresponding chemical species and $r_{\mathrm{Ca}}$ is the rate of $\mathrm{CaCO}_{3}$ formation. For example, it can be said that the dilution of neat seawater to $d=0.7$ slows the overall deposition rate of $\mathrm{CaCO}_{3}$ down to about half the rate for neat seawater. On the other hand, $\mathrm{Mg}(\mathrm{OH})_{2}$ crystallization is so fast that the deposition rate is controlled by the second or the third step, that is, a physical step. Hence, the dilution of seawater is considered to make difficult the $\mathrm{CaCO}_{3}$ deposition whose rate is controlled by the step 1 , but to give almost no effects on the $\mathrm{Mg}(\mathrm{OH})_{2}$ deposition whose rate is not controlled by the same step. All these satisfactorily explain the results in Fig. 3 . With decreasing $d$, the $W_{\text {Ca }}$ should decrease because of the increasing difficulty of the deposition, and the $W_{\mathrm{Mg}}$ must increase so as to compensate for the decrease in $W_{\mathrm{Ca}}$ and to keep the current efficiency, C.E., almost constant from $d=1$ to 0.1 (see Fig. 2).

Fig. 5 shows the variation in the ratio of extraction, $p_{\mathrm{i}}$, with $d$ for calcium or magnesium from seawater. The $p_{\mathrm{i}}$ is defined by

$$
p_{\mathrm{i}}=100 n_{\mathrm{i}} / n_{\mathrm{i} 0}
$$

where $n_{\mathrm{i}}$ and $n_{\mathrm{i} 0}$ are the moles of calcium or magnesium

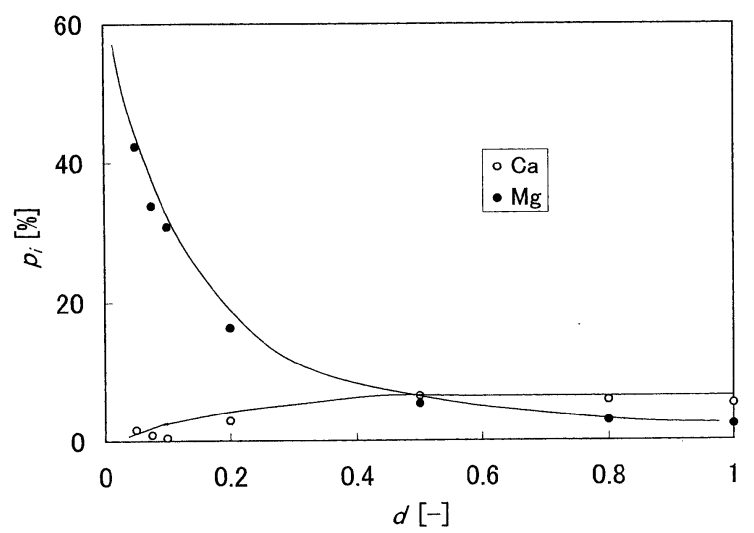

Fig. 5 Variation in the extraction ratio, $p_{\mathrm{i}}$, with $d$ for calcium or magnesium from seawater. The open and the closed circles are for $\mathrm{Ca}^{2+}$ and $\mathrm{Mg}^{2+}$, respectively. extracted to the deposit and those initially present in the seawater (or the diluted seawater) respectively. The $p_{\mathrm{i}}$ of magnesium increases with decreasing $d$, and reaches as high as $42 \%$ at $d=0.05$, while the $p_{\mathrm{i}}$ of calcium remains almost constant or somewhat decreases. Examination of the results in Fig. 5 leads us the conclusion that the lowering of the $W_{\mathrm{T}}$ or C.E. observed in Fig. 2 below $d=0.1$ comes mainly from the depletion of magnesium ions in the diluted seawater.

\subsection{Effect of dilution on deposit structure}

In order to examine the effect of dilution of seawater on the structure of calcareous deposits formed during $\mathrm{CP}$, the drying process of an electrodeposit was followed as a function of time $(t)$. The method of analyzing structure from a drying curve of a deposit has been detailed in the preceding paper ${ }^{5)}$. Fig. 6 shows a drying curve of the deposit formed from the seawater of $d=1$, where $W$ refers to the total weight of a steel cathode including a deposit. From the data in Fig. 6, we obtain a drying rate (i.e., $\mathrm{d} W / \mathrm{d} t$ ) vs. $\mathrm{t}$ curve as shown in Fig. 7. The first breaking point of this drying rate curve $\left(t=t_{\mathrm{a}}=13.6 \mathrm{~min}\right)$ corresponds to the point where the drying of the surface water on the deposit has just been completed. This point corresponds to $W=$ $83.4918 \mathrm{~g}$ in the curve in Fig. 6. Finally, we obtain the deposit weight including the pore-water, $W_{\mathrm{d}}$, by subtracting

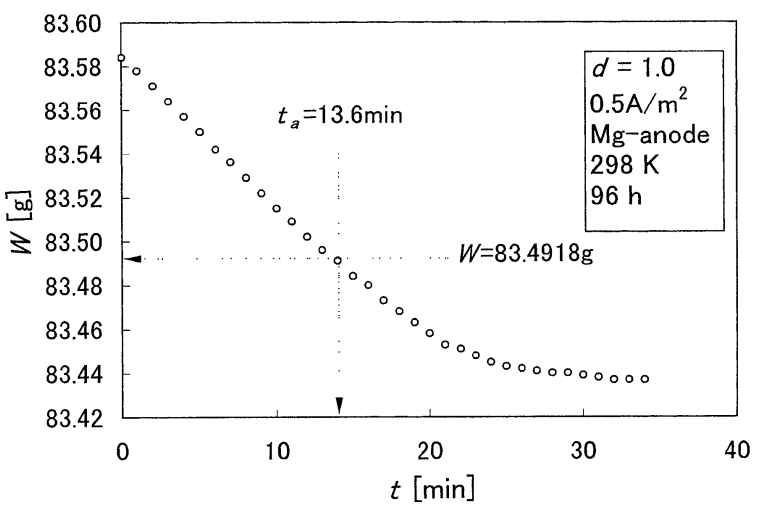

Fig. 6 A drying curve for the electrodeposit formed under the same conditions as presented in Fig. 2 at $d=1$. The $W$ refers to the total weight of a steel cathode including a deposit.

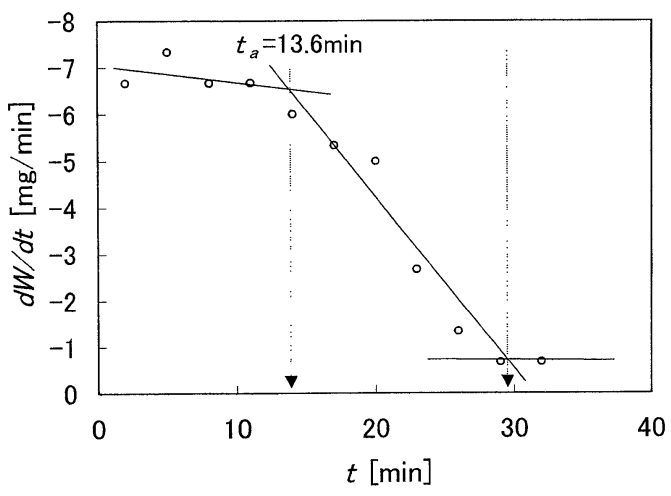

Fig. 7 The $\mathrm{d} W / \mathrm{d} t$ vs. $t$ curve derived from Fig. 6 . 
the weight of the steel cathode $(83.1367 \mathrm{~g})$ as $0.3551 \mathrm{~g}$. From the value of $W_{\mathrm{d}}$, the amounts of $\mathrm{CaCO}_{3}\left(W_{\mathrm{Ca}}\right)$ and $\mathrm{Mg}(\mathrm{OH})_{2}\left(W_{\mathrm{Mg}}\right)$ determined by the chemical analysis, and the relation,

$$
W_{\mathrm{d}}=W_{\mathrm{Ca}}+W_{\mathrm{Mg}}+W_{\mathrm{W}}
$$

we can evaluate the amount of pore-water, $W_{\mathrm{w}}$. From these values, we can evaluate the thickness $(\delta)$ and the porosity $(\varepsilon)$ of deposit film. The dependence of $\delta$ on $d$ presented in Fig. 8 may look somewhat contradictory, because $\delta$ increases sharply below $d=0.1$, and this trend is just reverse to that of the $W_{\mathrm{T}}$ vs. $d$ curve in Fig. 2 . The cause of this contradiction can partly be explained by Fig. 9 where the dependence of $\varepsilon$ on $d$ is presented. In the $\varepsilon$ vs. $d$ curve, there is a similar trend to that in the $\delta$ vs. $d$ curve. That is, the increase in $\delta$ below $d=0.1$ is responsible partly for the increase in the deposit porosity. However, problem is the origin of the porosity increase, itself. The $\mathrm{Mg} / \mathrm{Ca}$ ratio increases with decreasing $d$ especially below $d=0.1$, as shown in Fig. 3. Hence, it is reasonable to consider that the porosity increase should come from strong hydrophilic character of the surface of $\mathrm{Mg}(\mathrm{OH})_{2}$ solids, as compared with that of $\mathrm{CaCO}_{3}$ solids; the presence of hydrophilic $\mathrm{HO}-$ group in $\mathrm{Mg}(\mathrm{OH})_{2}$ will make $\mathrm{Mg}(\mathrm{OH})_{2}$ more hydrophilic than $\mathrm{CaCO}_{3}$. Accordingly, the increase of $\mathrm{Mg} / \mathrm{Ca}$ ratio in a deposit makes the water content and accordingly the porosity increase. Further, the fact that the density of $\mathrm{Mg}(\mathrm{OH})_{2}\left(2.34 \mathrm{~g} / \mathrm{cm}^{3}\right)$ is less than that of $\mathrm{CaCO}_{3}\left(2.71 \mathrm{~g} / \mathrm{cm}^{3}\right)$ causes $\delta$ to increase, when the $\mathrm{Mg} / \mathrm{Ca}$ ratio is increased. All these are considered to be responsible for the sharp increase in $\delta$ below $d=0.1$ found in Fig. 8 . This subject will further be studied in another paper.

\section{Conclusions}

The effects of dilution of seawater on the calcareous deposition accompanying cathodic protection of steel marine structures were studied. The results can be summarized as follows.

1. The dilution of seawater with distilled water gave few effects on the resulting total amount of calcareous deposits, until the dilution decreased the salinity to $1 / 10$ of the original value. Hence, in principle, the method of cathodic protection accompanied with calcareous deposition is applicable to ferrous structures in estuary areas with the salinity more than $1 / 10$ of the standard seawater under the conditions of present study.

2. However, the dilution significantly affected the composition of deposits; with the dilution, $\mathrm{Mg}(\mathrm{OH})_{2}$ content in the deposits increased, while $\mathrm{CaCO}_{3}$ content decreased. This variation in the deposit composition may be related to the slow crystallization rate of

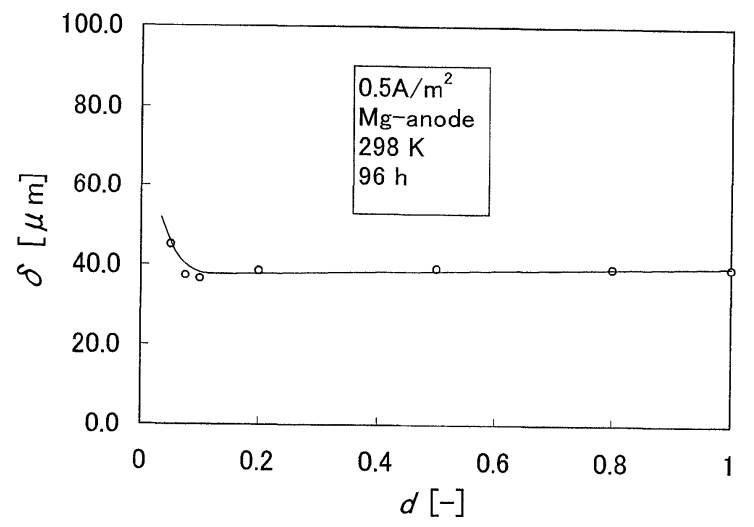

Fig. 8 Variation in the deposit thickness, $\delta$, with the seawater dilution ratio, $d$.

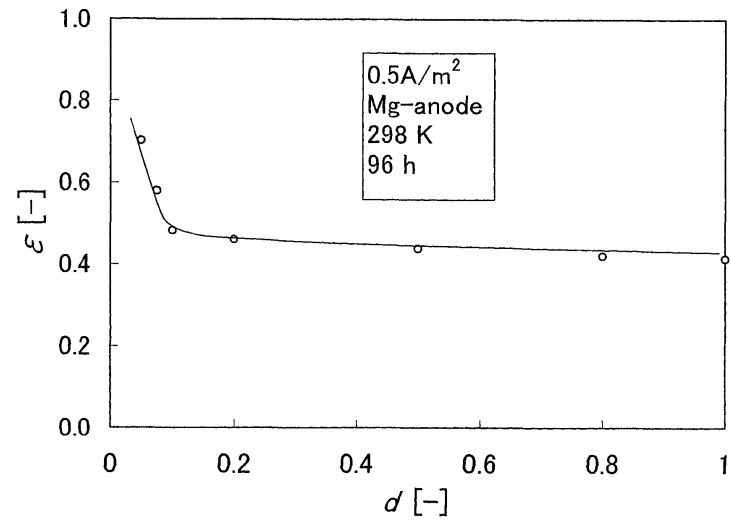

Fig. 9 Variation in the deposit porosity, $\varepsilon$, with the seawater dilution ratio, $d$.

$\mathrm{CaCO}_{3}$.

3. As for the structure of the deposit, the deposit thickness sharply increased when the dilution made the salinity less than $1 / 10$ of the standard seawater. This sharp increase in the deposit thickness mainly comes from the increase in the $\mathrm{Mg} / \mathrm{Ca}$ ratio in the deposits and the hydrophilic character of $\mathrm{Mg}(\mathrm{OH})_{2}$.

\section{References}

1) G. C. Cox, U. S. Patents No.2, 200, 469 (1940)

2) R. A. Humble, Corrosion, 4, 358 (1948).

3) F. L. Laque, "Marine Corrosion", John Wiley and Sons, p.104 (1975).

4) K. Akamine and I. Kashiki, Zairyo-to-Kankyo, 51, 496 (2002).

5) K. Akamine and I. Kashiki, Zairyo-to-Kankyo, 52, 401 (2003).

6) R. A. Berner, Geochimica et Cosmochimica Acta, 39, 489 (1975).

7) J. L. Bischoff, J. Geophys. Res., 75, 3315(1968).

8) J. -F. Yan, T.V. Nguyen and R.B. Griffin, J. Electrochem. Soc., 140, 733 (1993).

(Manuscript received September 11, 2003; in final form April 12, 2004) 